\title{
A INSERÇÃO DO JAPÃO NO TRATADO DE PARCERIA DO PACÍFICO (TPP)
}

\section{Silvio Yoshiro Mizuguchi Miyazaki}

Resumo: O Tratado de Parceria do Pacífico (TPP) é um dos mega acordos de integração econômica que está sendo negociado entre 12 nações, incluído o Japão. Este artigo analisa dados socioeconômicos e comerciais das nações componentes do tratado, e discute as reações domésticas e reações externas à participação do Japão no TPP.

Palavras-chave: TPP; integração econômica; acordos preferenciais de comércio; política comercial; geopolítica.

Abstract: The Trans-Pacific Partnership (TPP) is one of the mega agreements for economic integration has been negotiating among 12 nations, Japan included. This paper shows socioeconomic, and a trade analysis from the agreement's nations members, and discuss domestic and foreign reactions with the Japan's participation in the TPP.

Keywords: TPP; economic integration; preferential trade agreements; trade policy; geopolitics.

\section{Introdução}

Acordos preferenciais de comércio abrangendo o comércio de produtos ou de serviços, ou que contempla ambos, aumentaram a partir de meados dos anos de 1990, sendo que atualmente existem cerca de 600 deles. Esses acordos têm sido firmados para formação de zonas de livre comércio ou de uniões aduaneiras, entre dois ou mais países. Cerca de $90 \%$ dos acordos existentes são de zonas de livre comércio e $10 \%$ de uniões aduaneiras (WTO: 2016).

Há também os acordos de investimento entre os países, segundo a UNCTAD (2016), há 2962 tratados bilaterais de investimento, sendo que 2322 estão em vigor, e 363 acordos internacionais de investimento e os que o inclui, sendo 293 em vigor.

1 Professor de Economia da Escola de Artes, Ciências e Humanidades (EACH) e do Programa de PósGraduação em Língua, Literatura e Cultura Japonesa da Universidade de São Paulo (USP). Doutor em Economia pela Fundação Getúlio Vargas (FGV); symiyazaki@usp.br. 
Os tratados e acordos de parceria econômica são aqueles que incluem tanto comércio quanto investimento, assim como ajuda ao desenvolvimento, tais como os que a União Europeia tem com as antigas colônias. Existem os que podem abranger adicionalmente, além dos aspectos de comércio e investimento, a mobilidade da mão de obra e a propriedade intelectual, tais como os acordos do Japão com países do Sudeste Asiático. Portanto, são acordos entre países no aspecto econômico que abrangem não somente o fluxo de produtos e serviços, mas também de fatores de produção.

Os mega acordos de integração econômica tem sido denominados como parceria econômica, uma vez que provisões tradicionais de acesso a mercados, tais como tarifas, barreiras não tarifárias, técnicas, fitossanitárias, e não tradicionais, como serviços, compras governamentais, propriedade intelectual, meio ambiente, trabalho, empresas do governo, disputas investidor-Estado, investimento. Outra característica é dos países membros forem áreas economicamente grandes e tendo participação de países com economicamente importantes entre Estados Unidos, Japão e União Europeia.

São três os mega acordos de integração econômica que estão em fase de estudos, de negociações ou de ratificação parlamentar (AGGARWAL, 2016; COOPER, 2014): TTIP (Transatlantic Trade and Investment Partnership), entre os Estados Unidos e a União Europeia; o RCEP (Regional Comprehensive Economic Partnership): os 10 países que compõem o Asean, a China, a Coreia do Sul, o Japão, a Índia, a Austrália e a Nova Zelândia; o TPP (Trans Pacific Partnership), em português, Tratado da Parceria do Pacífico, que é o objeto do artigo.

A literatura brasileira concernente ao TPP é relativamente escassa, tendo sido analisado, entre outros, por AMARAL \& MATTOS (2013), CARNEIRO (2014), COZENDEY \& GURGEL (2016), LINS (2014), RIBEIRO (2015), SILVA (2016), THORSTENSEN \& FERRAZ (2014). A influência dos Estados Unidos para a elaboração das normas do TPP e seus impactos geopolíticos, especialmente no que tange à China, é discutida por AMARAL \& MATTOS (2013) e por SILVA (2016). Análises concernentes à abrangência das provisões do TPP, bem como os efeitos geopolíticos internacionais e ao Brasil são apresentadas em CARNEIRO (2014), COZENDEY \& GURGEL (2016) e LINS (2014). As consequências dos mega acordos TTIP e TPP para a economia brasileira, através de simulações de redução de barreiras tarifárias e não tarifárias são analisadas por THORSTENSEN \& FERRAZ (2014). Os efeitos do TPP no setor da saúde são estudados por RIBEIRO (2015).

O Japão, apesar de ser a terceira economia do mundo, de ter a maior renda per capita da Ásia, as implicações no âmbito da economia política da sua participação no TPP não tem sido objeto direto dos estudos no Brasil. Para contribuir com essa discussão, o presente artigo trata inicialmente em analisar a evolução do tratado, assim como uma caracterização dos aspectos socioeconômicos e comerciais das nações componentes do tratado, e em seguida discute as reações domésticas e reações externas à participação do Japão no TPP. 


\section{Evolução e caracterização do TPP}

O TPP originou-se de um pequeno acordo de livre comércio. Chile, Cingapura e Nova Zelândia iniciaram negociações em 2002, com vistas a formar uma zona de livre comércio, sendo que Brunei incorpora-se às negociações em 2005. No ano seguinte, entra em vigor um acordo de livre comércio entre essas economias denominado como P4. Em 2008, os Estados Unidos anunciaram o interesse em se integrar e ampliar esse acordo, o que despertou a atenção das empresas e dos governos. Nesse mesmo ano, Austrália, Peru e Vietnã são incluídos nas conversações. No final de 2009, tem início as negociações formais para constituir o Tratado de Parceria do Pacífico, o TPP. Mais economias iniciaram suas participações nas negociações: Malásia, a partir de 2010, e o Canadá e o México a partir de 2011. O Japão foi a última economia a ingressar nas negociações, em 2013 (GAO, 2012; ELMS, 2015: 1-4). Em outubro de 2015, as negociações entre os governos são finalizadas, mas para a entrada em vigor do tratado, ainda há que se aguardar até o final de 2017 para a ratificação do tratado pelos parlamentos das nações componentes do TPP.

As nações que comporiam o TPP localizam-se em economias de diferentes subregiões do Pacífico: Brunei, Cingapura, Malásia e Vietnã estão no Sudeste Asiático; Austrália e Nova Zelândia na Oceania; Canadá, Estados Unidos e México na América do Norte; Chile e Peru na América do Sul e o Japão no Leste Asiático. São economias de tamanhos e graus de desenvolvimento diferentes, tal como podem ser observadas na tabela 1.

O TPP representaria 36,00 \% do PIB mundial e 11,20 \% da população mundial, portanto, um mercado significativo. No seu conjunto tem um PIB maior que a União Europeia e o Nafta (PALIT: 2014: 4).

Há economias dentro do bloco em que as participações do PIB no total do mundo são relativamente grandes, tal como os Estados Unidos (22,30 \%) e o Japão (5,90 \%) e outras que não atingem décimos percentuais como Brunei $(0,02 \%)$. Há países populosos como, novamente, os Estados Unidos e o Japão, e não populosos como Brunei. Quanto ao PIB per capita, há oito economias que são consideradas nações de renda alta, três nações com renda média-alta, e uma nação com renda média-baixa ${ }^{2}$ (vide tabela 1 ).

Essa heterogeneidade dos membros faz com que as economias serem complementares, propiciando trocas comerciais com vantagens comparativas e com ganhos econômicos aos países membros (PETRI \& PLUMMER, 2016).

A abrangência de temas do TPP é bastante grande: há as provisões típicas de qualquer acordo comercial a respeito de acesso a mercados, tais como tratamento nacional e acesso a mercados, regras de origem, têxteis e vestuário, aduana e facilitação de comércio, salvaguardas, medidas fitossanitárias, barreiras técnicas, disputas comerciais;

2 Conforme classificação do World Bank (2016), nações de renda baixa são as que têm renda inferior a US\$1045, de renda média-baixa são as que têm renda entre US\$ 1046 e US\$ 4125, de renda médiaalta são as que têm renda entre US\$ 4126 e US\$ 12735 , e as de renda alta as que têm renda superiores a US\$ 12736 . 
há as que estão sendo discutidas no âmbito da $\mathrm{OMC}$, tais como comércio de serviços, serviços financeiros, telecomunicações, comércio eletrônico, licitações públicas, propriedade intelectual. E outras que não se discutem na $\mathrm{OMC}$, tais como mobilidade de executivos e questões trabalhistas, empresas do governo e monopólios, facilitação de negócios, pequenas e médias empresas, regulação, transparência, desenvolvimento e meio ambiente (PALIT, 2014). Apesar dessa amplitude, nesta seção, a análise será limitada ao comércio.

Os dados de comércio das economias do TPP são mostrados na tabela 2. Em bloco, o TPP representa 23,1 \% das exportações mundiais e $27,4 \%$ das importações mundiais. $\mathrm{O}$ grau de abertura comercial tem uma variância relativamente grande pelo fato da diversidade das economias que compõe o TPP. Austrália, Estados Unidos e Japão tem um grau de abertura relativamente pequeno uma vez que são economias de renda alta, portanto, uma concentração grande no setor de serviços e não mais de comércio de produtos, enquanto Brunei, Cingapura, Malásia e Vietnã são economias relativamente pequenas territorialmente e com dependência maior no comércio exterior, sendo Brunei um produtor e exportador de petróleo, Cingapura um entreposto comercial, o que resulta em grau de abertura comercial grande.

O número de acordos preferenciais de comércio de cada nação membro do TPP é mostrado na tabela 3. Pode-se observar que cada economia tem uma quantidade relativamente grande de acordos comerciais, destacando-se o Chile com 24 e Cingapura com 21 deles.

A tabela 4 mostra uma matriz apontando os acordos bilaterais de comércio entre economias do TPP. O Japão tem o maior número de acordos com 8 , seguido da Austrália, Chile e Nova Zelândia, cada um com 5. Somente o Canadá não tem acordos bilaterais, entretanto integra a zona de livre comércio da NAFTA com os Estados Unidos e o México.

Além dos acordos bilaterais de comércio, as economias do TPP pertencem a instituições regionais, que propiciam a abertura comercial entre os membros, o que é mostrado na tabela 5. Todas as nações do TPP pertencem à APEC (Asia Pacific Economic Cooperation); Brunei, Cingapura, Malásia e Vietnã pertencem à ASEAN (Association of Southeast Asian Nations), Canadá, Estados Unidos e México formam a NAFTA (North America Free Trade Area) e os países da ASEAN, Austrália e Nova Zelândia compõem a AANFTA (Asean-Australia-New Zealand Free Trade Area).

A multiplicidade de acordos preferencias de comércio tem como efeito economicamente negativo o spaguetti bowl e aumento de custos de transação. O fenômeno do spaguetti bowl ocorre quando uma nação firma diferentes acordos comerciais que resultam na diversidade e emaranhado de regras de origem e regulações de comércio, o que provoca a elevação de altos custos de transação para as empresas e para os governos (BHAGWATI, GREENAWAY \& PANAGARIYA, 1998).

Como pode ser analisado pelas tabelas 4 e 5 , as economias componentes do TPP pertencem a diversos acordos de comércio bilaterais e regionais o que faz com que haja 
altos custos de transação pelo spaguetti bowl. O TPP, harmonizando as cláusulas dos acordos entre os seus membros agregando num só tratado, poderia diminuir os custos de transação (MENON: 2014: 471-472; PETRI \& PLUMER, 2016: 5).

O que desperta atenção no TPP é a sua abrangência uma vez que este acordo, sendo uma parceria econômica, inclui o comércio de bens, com regras de acesso a mercados, tais como tratamento nacional e acesso a mercados, regras de origem, têxteis e vestuário, aduana e facilitação de comércio, salvaguardas, medidas fitossanitárias, barreiras técnicas, disputas comerciais, mas também o comércio de serviços, tais como serviços financeiros, telecomunicações, comércio eletrônico, licitações públicas e propriedade intelectual. Além disso, no TPP estão contempladas as regras relativas à mobilidade de executivos e questões trabalhistas, monopólios governamentais, facilitação de negócios, pequenas e médias empresas, investimento (PALIT: 2014: 5).

\section{O Japão no TPP}

Em 2010 houve o anúncio pelo Japão em seu interesse em participar do TPP, sendo que em 2013 aderiu formalmente as negociações.

Segundo COOPER \& MANYIN (2013: 1-2), "Como a segunda maior economia da Ásia, a terceira maior economia do mundo, e um elo fundamental nas cadeias de suprimentos e produtivas, a participação do Japão no TPP seria essencial para melhor a credibilidade e a viabilidade do TPP como um arranjo regional de livre comércio". Ademais, o ingresso do Japão no TPP na prática é a formação de uma área preferencial de comércio com os Estados Unidos.

A participação do Japão no TPP propiciaria o acesso sem precedentes ao mercado japonês para exportadores e investidores estrangeiros. Forçaria o governo japonês a enfrentar os problemas econômicos estruturais que tem impedido o seu crescimento econômico por longo tempo, de forma que seria uma oportunidade para possíveis reformas econômicas domésticas estruturais para reavivar a economia do país. Também simbolizaria a posição do Japão como uma potência econômica no Leste Asiático, ofuscada pelas décadas de estagnação econômica e pelo crescimento da China (COOPER \& MANYIN, 2013: 2; NCAF: 57).

\subsection{Reações domésticas ao TPP}

Domesticamente ao Japão, houve grupos pró e contra as negociações ao TPP. Se de um lado o grande empresariado industrial e comercial estava apoiando, de outro lado o setor agrícola era contra a entrada do Japão ao TPP. Também havia internamente ao governo japonês, órgãos que avaliavam positivamente e outros negativamente os efeitos do TPP ao Japão.

A comunidade de negócios representada pelo Keidanren (Federação das Organizações Econômicas do Japão) e pela Câmara Japonesa de Comércio e Indústria, 
além do Ministério da Economia, Comércio Internacional e Indústria e o Gabinete do Primeiro Ministro apoiaram o ingresso do Japão nas negociações do TPP. Esse apoio foi essencial para poder moldar o tratado de acordo com os interesses das empresas japonesas no que se refere, por exemplo, as regras de origem e de propriedade intelectual (TERADA, 2012: 2; JAMITZKY, 2015: 9).

Um exemplo de apoio foi a promoção de mais de sessenta seminários informativos sobre o TPP realizados pela Câmara Japonesa de Comércio e Indústria aos seus membros e ao público em geral (JAMITZKY, 2015: 9).

Os grupos oponentes à entrada do Japão ao TPP eram principalmente os relacionados ao setor agrícola, inclusive dentro do governo japonês pelo Ministério da Agricultura, Floresta e Pesca. O setor agrícola tem sido largamente protegido por uma série de medidas tarifárias, com altas tarifas, principalmente ao arroz, e barreiras não tarifárias. A agricultura japonesa é centrada na rizicultura, cujo cultivo é realizado em pequenas propriedades (ARITA, DYCK, MARQUARDT, 2015; ARITA \& DYCK, 2014: 5-6, 8; TERADA, 2012: 3).

Com o ingresso no TPP, o Japão teria que reduzir o protecionismo no setor pela eliminação de tarifas e tarifas-quotas na agricultura, causando competição externa frente aos produtos agrícolas domésticos, com o aumento das importações dos seus países membros, e, consequentemente, menos ganhos aos proprietários de terras (ARITA \& DYCK, 2014: 5-6, 8). Com o TPP, o Japão deverá abolir tarifas em $81 \%$ dos seus produtos agrícolas, florestais e marítimos (NISHIKAWA, 2016). O Zenchîu (Sindicato Central das Cooperativas Agrícolas) e o Ministério da Agricultura, Floresta e Pesca do Japão se opuseram ao ingresso do país nas negociações do TPP (TERADA, 2012: 3).

A título de ilustração no que se refere a produtos agrícolas, o tratado prevê que as tarifas japonesas para carne bovina in natura ou congelada seja diminuída de 38,5\% para $9 \%$ ad valorem no prazo de 16 anos, para carne suína a diminuição da tarifa de 4,3 \% para 2,2 \% ad valorem no prazo de 9 anos, a eliminação de tarifas para produtos derivados de açúcar e adoçante, como doces, chocolates, produtos de confeitaria, a eliminação de tarifas para cigarros e charutos no prazo de 11 anos (FERGUSSON, McMINIMY; WILLIAMS, 2015: 4-5). Tarifas menores ou eliminadas significariam maior competição aos produtores agrícolas japoneses.

A adesão do Japão ao TPP é considerada como parte da reforma da estrutura econômica que o governo japonês está implantando através da política econômica denominada Abenomics (PEMPEL, 2015: 363-369; ROGOWSKY \& HOLICK, 2014). Com o ingresso no TPP, o Japão faria uma liberalização numa escala maior do que em outros acordos comerciais anteriormente firmados, resultando numa maior competição aos setores econômicos japoneses o que proporcionaria maior eficiência e preços menores aos consumidores japoneses (SUGAWARA, 18: 2015). 


\subsection{Reações externas ao TPP}

A decisão do Japão em ingressar nas negociações do TPP tornou-se um evento que modificou a corrida por acordos preferenciais de comércio no Pacífico Asiático (SOHN, 2015: 357).

Após o Japão ter anunciado o interesse em participar do TPP, a China e a Coreia do Sul começaram a acelerar as negociações de acordos de preferências comerciais com outros países (TERADA, 2012: 1).

O ingresso do Japão no TPP reequilibraria as forças geopolíticas na região do pacífico asiático, uma vez que a China persegue seus próprios arranjos econômicos bilaterais e multilaterais, que pode moldar a arquitetura econômica da Ásia. A inclusão do Japão, como a segunda maior economia e a mais rica economicamente em renda per capita na Ásia, no TPP transformaria visões alternativas de regras regionais de comércio. Adicionalmente, a participação do Japão e dos Estados Unidos numa mesma área de livre comércio poderia ser visto como um meio de reafirmar a sua aliança (COOPER \& MANYIN, 2013: 12 e 13).

Desse modo, os Estados Unidos seriam um dos países que teriam resultados positivos nos seus interesses geoestratégicos pelo ingresso do Japão no TPP, pois além de reequilibrar as influências das nações no Pacífico Asiático, seria um reforço no engajamento norte-americano na região (PEMPEL, 2015:367; TERADA, 2012: 1).

\section{Conclusão}

O Japão foi a última nação a ingressar nas negociações do TPP, Tratado da Parceria do Pacífico, em 2103. Entre os países membros que estão negociando o tratado, o Japão é o a segunda maior economia e também a segunda nação mais populosa. Em termos de comércio, tanto exportações quanto importações, o Japão também figura como a segunda. A adesão do Japão ao TPP tornou o acordo maior economicamente.

Em relação aos acordos bilaterais de comércio, o Japão tem o maior número entre os membros do TPP de forma que quando da implantação do acordo, os custos de transação tanto para as empresas quanto para o governo devem diminuir.

$\mathrm{O}$ efeito do TPP para a economia japonesa deve ser positivo, uma vez que haverá pressão por reformas econômicas estruturais, que são necessárias para retomar o crescimento econômico do país. Pode propiciar maior eficiência a alguns setores econômicos, tal como a agrícola, com a maior concorrência internacional, por uma possível diminuição de preços de produtos aos consumidores pela redução ou abolição de tarifas às mercadorias importadas de países membros do tratado.

Considerações geopolíticas são de que o TPP pode contribuir para uma nova aliança entre o Japão e os Estados Unidos para diminuir a influência e o protagonismo da China na região do Pacífico. 


\section{Referências Bibliográficas}

AGGARWAL, Vinod K. Mega-FTAs and the Trade-Security Nexus: The Trans-Pacific Partnership (TPP) and the Regional Comprehensive Economic Partnership (RCEP). Asia Pacific Issues, Honolulu, n. 123, pp. 1-8, mar. 2016.

AMARAL, Gabriela Granço do \& MATTOS, Thais Caroline Lacerda. A Parceria Trans-Pacífico como uma estratégia de contenção da China. Aurora, Marília, v. 7, n. 1, pp. 111-134, jul.-dez. 2013.

ARITA, Shawn S. \& DYCK, John. Vietnam's Agri-Food Sector and the Trans-Pacific Partnership, EIB-130, Washington, U.S. Department of Agriculture, Economic Research Service, out. 2014.

ARITA, Shawn; John DYCK \& David MARQUARDT (2015). Japan, Vietnan, and the Asian Model of Agricultural Development and Trade. Amber Waves, Washington, n. 1. fev. 2015.

BHAGWATI, Jagdish, David GREENAWAY and Arvind PANAGARIYA. Trading preferentially: theory and policy. The Economic Journal, Oxford, v. 108, n. 449, pp. 1128-1148, jul. 1998.

CARNEIRO, Flavio Lyrio. A Parceria Transpacífica: principais características e impactos sobre a regulação do comércio mundial. Boletim de Economia e Política Internacional, Brasília, n. 18, pp. 59-72, set.-dez., 2014.

COZENDEY, Carlos Márcio Bicalho \& GURGEL, Ivana Marília. A Parceria Transpacífico e suas consequências para o Brasil: uma aproximação preliminar. Cadernos de Política Exterior, Brasília, ano II, v. 3, pp. 141-157, $1^{\text {o }}$ semestre, 2016.

COOPER, William H. Free Trade Agreements: Impact on U.S. Trade and Implications for U.S. Trade Policy. Current Politics and Economics of the United States, Canada and Mexico, New York, v. 16, n. 3, pp. 425-445, jul.-set. 2014.

COOPER, William H. \& MANYIN, Mark E. (2013). Japan Joins the Trans-Pacific Partnership: What Are the Implications? CRS Report for Congress R42676. Washington: Library of Congress, Congressional Research Service, 2013.

ELMS, Deborah K..The Origins and Evolution of the Trans-Pacific Partnership (TPP) Trade Negotiations. Asian Trade Centre Working Paper. Singapore, jan. 2015.

FERGUSSON, Ian F.; McMINIMY, Mark A. ; WILLIAMS, Brock R. The Trans-Pacific Partnership (TPP): In Brief. CRS Report for Congress R42678. Washington: Library of Congress, Congressional Research Service, 2015.

GAO, Henry. From the P4 to the TPP transplantation or transformation? In: LIM, C.L., Deborah K. ELMS and Patrick LOW (orgs.).The Trans-Pacific Partnership a quest for a twenty-first century trade agreement. New York: Cambridge University Press, 2012. Chapter 4, pp. 64-81.

JAMITZKY, Ulli. Diffusion of Japanese preferential trade agreements: Why is no evaluation underway? The Japanese Political Economy. Philadelphia, v. 41, n. 1-2, pp. 1-13, 2015.

LINS, Hoyêdo Nunes. Novas geometrias no capitalismo global: a Parceria Trans-Pacífico. Contexto Internacional. Rio de Janeiro, v. 36, n.2, pp. 623-653, jul.-dez. 2014.

MENON, Jayant. From Spaghetti Bowl to Jigsaw Puzzle? Fixing the Mess in Regional and Global 
Trade. Asia \& the Pacific Policy Studies, Canberra, v. 1, n. 3, pp. 470-483, set. 2014.

NCAF (National Committee on American Foreign Policy). Priorities in Trade Policy - The Trans-Pacific Partnership Agreement. American Foreign Policy Interests, New York, v. 37, n. 1, pp. 57-58, abr. 2015.

NISHIKAWA, Kunio. Free Trade and the Future of Japan's Agricultural Policy. Asia Pacific Bulletin, Washington, n. 342, 2016.

PALIT, Amitendu. The Trans-Pacific Partnership: identifying the implications. Asia Pacific World, Beppu, v. 5, n. 2, pp. 4-11, Autumn, 2014.

PETRI, Peter A. \& PLUMMER, Michael G. The Economic Effects of the Trans-Pacific Partnership: New Estimates. Working Paper Series WP 16 - 2. Washington: Peterson Institute for International Economics, 2016.

PEMPEL, T. J. Back to the Future ? Japan's Search for a Meaningful New Role in the Emerging Regional Order. Asian Perspective, Boulder, v. 39, n. 3, pp. 361-380, jul.-set. 2015.

RIBEIRO, Helena. Free-trade agreements: challenges for global health. Revista de Saúde Pública, São Paulo, v. 49, n. 52, pp. 1-4, ago. 2015.

ROGOWSKY, Robert A. \& HOLICK, Gary. TPP and the Political Economy of U.S.-Japan Trade Negotiations. Washington: Wilson Center, 2014.

SCHOTT, Jeffrey J. The United States, Japan, and The Trans-Pacific Partnership. In: Peterson Institute for International Economics. Lessons from Decades Lost: Economic Challenges and Opportunities Facing Japan and the United States. Washington: Peterson Institute for International Economics, 2014: pp. $56-65$.

SILVA, Daniel Martins. A expansão para o Oeste: a Parceria Transpacífica sob a perspectiva dos Estados Unidos. Dissertação de Mestrado. Programa de Pós-Graduação em Relações Internacionais. PUC-SP, UNESP e Unicamp. 2016.

SOHN, Yul. The "Abe Effect" in Northeast Asia: The Interplay of Security, Economy, and Identity. Asian Perspective, Boulder, v. 39, n. 3, pp. 357-360, jul.-set. 2015.

SUGAWARA, Junichi. Trans-Pacific Partnership and Japan's Trade Policy. Social Science Japan, Tokyo, v. 52, pp. 17 - 20. mar. 2015.

TERADA, Takashi. Japan and the Trans-Pacific Partnership. Washington: SPFUSA, 2012.

THORSTENSEN, Vera \& FERRAZ, Lucas (coord.) (2014). The impacts of TTIP and TPP on Brazil. São Paulo: EESP-FGV Centro do Comércio Global e Investimento, 2014.

UNCTAD. International Investment Agreements Navigator. Disponível em: <http:// investmentpolicyhub.unctad.org/IIA>. Acesso em: 14 jan. 2016.

WORLD BANK. New Country Classifications. Disponível em: <http://blogs.worldbank.org/ opendata/new-country-classifications $>$. Acesso em: 14 de jan. 2016.

WTO. Regional Trade Agreements: facts and figures. Disponível em: <https://www.wto.org/ english/tratop_e/region_e/region_e.htm>. Acesso em: 14 jan. 2016. 


\section{ANEXOS}

TABELA 1 - Dados socioeconômicos: PIB, PIB per capita e população em 2014

\begin{tabular}{|c|c|c|c|c|c|}
\hline Economia & $\begin{array}{l}\text { PIB em } \\
2014 \\
\text { (preços } \\
\text { correntes } \\
\text { em US\$ } \\
\text { bilhões) }\end{array}$ & $\begin{array}{l}\mathrm{PIB} / \\
\mathrm{PIB} \\
\text { mundo }\end{array}$ & $\begin{array}{l}\text { PIB per } \\
\text { capita } \\
\text { em } 2014 \\
\text { (preços } \\
\text { correntes } \\
\text { em US\$) }\end{array}$ & $\begin{array}{l}\text { População } \\
\text { (mil) }\end{array}$ & $\begin{array}{l}\text { População/ } \\
\text { População } \\
\text { total }\end{array}$ \\
\hline Austrália & 1455 & $1,90 \%$ & 61980 & 23470 & $0,30 \%$ \\
\hline Brunei & 17 & $0,02 \%$ & 40980 & 417 & $0,01 \%$ \\
\hline Canadá & 1785 & $2,30 \%$ & 50231 & 35544 & $0,50 \%$ \\
\hline Chile & 258 & $0,30 \%$ & 14528 & 17763 & $0,20 \%$ \\
\hline Cingapura & 308 & $0,40 \%$ & 56284 & 5470 & $0,10 \%$ \\
\hline Estados Unidos & 17419 & $22,30 \%$ & 54629 & 318857 & $4,40 \%$ \\
\hline Japão & 4601 & $5,90 \%$ & 36194 & 127132 & $1,80 \%$ \\
\hline Malásia & 338 & $0,40 \%$ & 11307 & 29902 & $0,40 \%$ \\
\hline México & 1295 & $1,70 \%$ & 10326 & 125386 & $1,70 \%$ \\
\hline Nova Zelândia & 200 & $0,30 \%$ & 44342 & 4510 & $0,10 \%$ \\
\hline Peru & 203 & $0,30 \%$ & 6541 & 30973 & $0,40 \%$ \\
\hline Vietnã & 186 & $0,20 \%$ & 2052 & 90729 & $1,20 \%$ \\
\hline TPP & 28065 & $36,00 \%$ & 32450 & 810152 & $11,20 \%$ \\
\hline Mundo & 77961 & & 10739 & 7259692 & \\
\hline
\end{tabular}

Fonte: World Bank. World Development Indicators database.

Observação: tabela elaborada pelo autor. 
TABELA 2 - Comércio: abertura, exportações e importações em 2014

\begin{tabular}{|c|c|c|c|c|c|}
\hline Economia & $\begin{array}{l}\text { Abertura } \\
\text { comercial } \\
\text { (Corrente } \\
\text { de } \\
\text { Comércio/ } \\
\text { PIB país) }\end{array}$ & $\begin{array}{l}\text { Exportações } \\
\text { (US\$ } \\
\text { bilhões) }\end{array}$ & $\begin{array}{l}\text { Exportações/ } \\
\text { Exportações } \\
\text { mundiais }\end{array}$ & $\begin{array}{l}\text { Importações } \\
\text { (US\$ bilhões) }\end{array}$ & $\begin{array}{l}\text { Importações/ } \\
\text { Importações } \\
\text { mundiais }\end{array}$ \\
\hline Austrália & $42,3 \%$ & 241 & $1,3 \%$ & 237 & $1,2 \%$ \\
\hline Brunei & $106,64 \%$ & 11 & $0,1 \%$ & 4 & $0,1 \%$ \\
\hline Canadá & $64,14 \%$ & 475 & $2,5 \%$ & 480 & $2,5 \%$ \\
\hline Chile & $66,07 \%$ & 76 & $0,4 \%$ & 72 & $0,4 \%$ \\
\hline Cingapura & $350,85 \%$ & 410 & $2,2 \%$ & 366 & $1,9 \%$ \\
\hline $\begin{array}{l}\text { Estados } \\
\text { Unidos }\end{array}$ & $29,93 \%$ & 1621 & $8,5 \%$ & 2413 & $12,6 \%$ \\
\hline Japão & $38,55 \%$ & 690 & $3,6 \%$ & 812 & $4,3 \%$ \\
\hline Malásia & $138,46 \%$ & 234 & $1,2 \%$ & 209 & $1,1 \%$ \\
\hline México & $65,86 \%$ & 397 & $2,1 \%$ & 412 & $2,2 \%$ \\
\hline $\begin{array}{l}\text { Nova } \\
\text { Zelândia }\end{array}$ & $56,56 \%$ & 42 & $0,2 \%$ & 43 & $0,2 \%$ \\
\hline Peru & $46,32 \%$ & 40 & $0,2 \%$ & 42 & $0,2 \%$ \\
\hline Vietnã & $169,53 \%$ & 150 & $0,8 \%$ & 148 & $0,8 \%$ \\
\hline ТРP & & 4385 & $23,1 \%$ & 5237 & $27,4 \%$ \\
\hline
\end{tabular}

$59,21 \%$

18995

19104

Fonte: WTO Statistics Database.

Observação: tabela elaborada pelo autor. 
TABELA 3 - Número de acordos preferenciais de comércio

Economia Número de acordos preferenciais de comércio

Austrália

12

Brunei

8

Canadá

11

Chile

Cingapura

21

Estados Unidos

Japão

Malásia

12

México

11

Nova Zelândia

11

Peru

14

Vietnã

Fonte: WTO Regional Trade Agreements Information System

Observação: tabela elaborada pelo autor. 
TABELA 4 - Acordos bilaterais de comércio entre economias do TPP

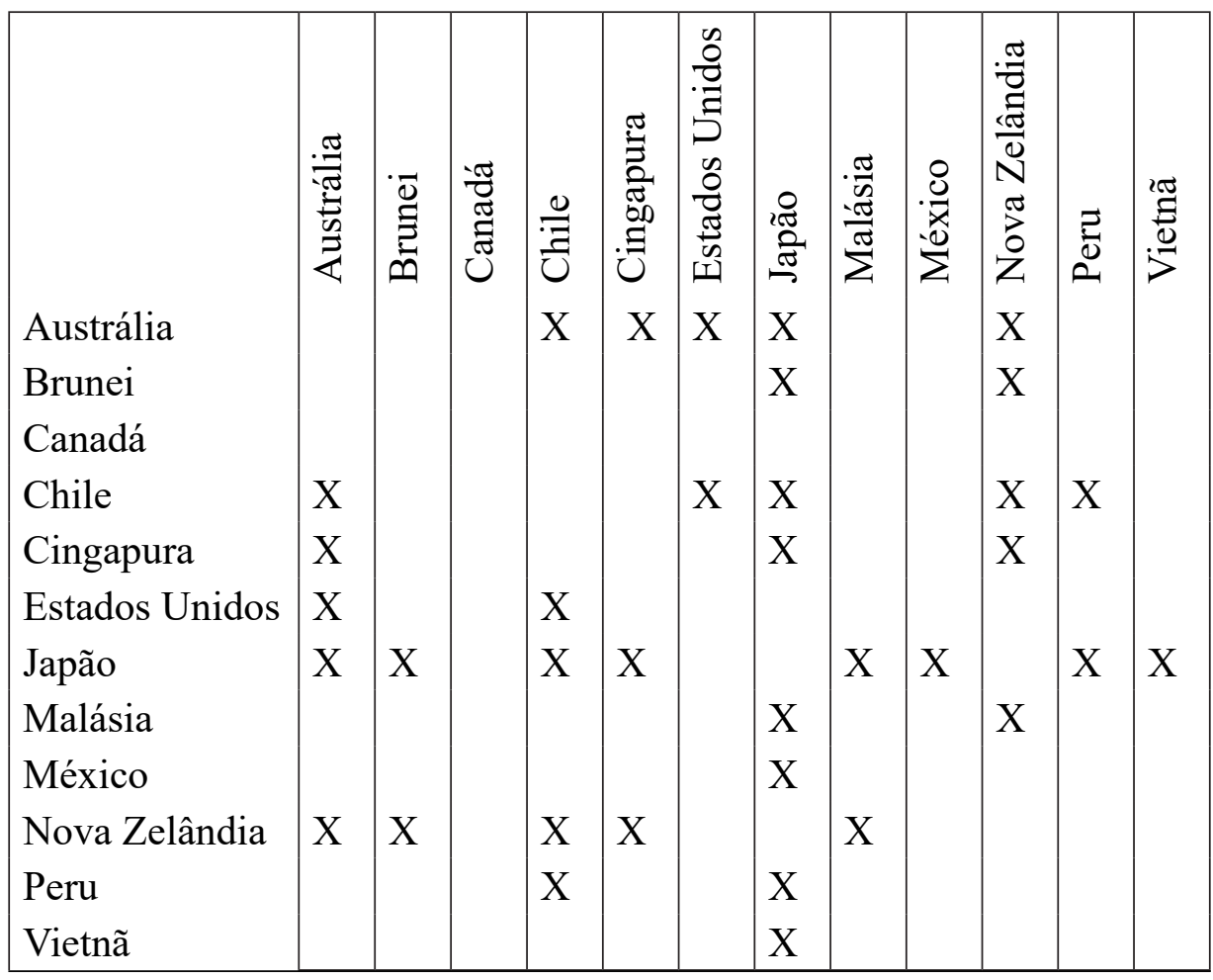

Fonte: WTO Regional Trade Agreements Information System Observação: tabela elaborada pelo autor. 
TABELA 5 - Economias do TPP pertencentes a instituições regionais

\begin{tabular}{|l|c|c|c|c|}
\hline & APEC & ASEAN & NAFTA & AANZFTA \\
Bustrália & $\mathrm{X}$ & & & $\mathrm{X}$ \\
Canadá & $\mathrm{X}$ & $\mathrm{X}$ & & $\mathrm{X}$ \\
Chile & $\mathrm{X}$ & & $\mathrm{X}$ & \\
Cingapura & $\mathrm{X}$ & & & $\mathrm{X}$ \\
Estados Unidos & $\mathrm{X}$ & $\mathrm{X}$ & & \\
Japão & $\mathrm{X}$ & $\mathrm{X}$ & \\
Malásia & $\mathrm{X}$ & & & $\mathrm{X}$ \\
México & $\mathrm{X}$ & $\mathrm{X}$ & & \\
Nova Zelândia & $\mathrm{X}$ & & $\mathrm{X}$ & $\mathrm{X}$ \\
Peru & $\mathrm{X}$ & & & \\
Vietnã & $\mathrm{X}$ & $\mathrm{X}$ & & $\mathrm{X}$ \\
\hline
\end{tabular}

Fonte: WTO Regional Trade Agreements Information System

Observação: tabela elaborada pelo autor. 